\title{
doispontos:
}

\section{A dimensão ética do corpo nos pensamentos de Schopenhauer e de Freud}

\author{
Marinella Morgana de Mendonça ${ }^{1}$
}

Resumo: Este escrito sintetiza nossa pesquisa de doutorado. A mesma não é uma análise exegética das teorias de Schopenhauer e de Freud, mas busca comprovar e justificar a existência de uma problemática fundante e comum a ambos: responder ao enigma imposto pelo corpo e suas implicações para a ética. O nosso objetivo é, pois, investigar o corpo e as consequências éticas oriundas da abordagem desse objeto por nossos autores. O corpo não é apenas um objeto de ciência, mas carrega uma dimensão irredutível do homem para ambos. Optamos por entrelaçar, ao longo do texto, as concepções do corpo nos dois autores, ressaltando algumas semelhanças e diferenças que nos permitem dizer do estatuto ético desse objeto nas obras do filósofo e do psicanalista.

Palavras-chave: Schopenhauer; metafísica da vontade; Freud; metapsicologia; corpo; ética da compaixão.

Abstract: This writing is a synthesis of our doctoral research, which is not an exegetical analysis of Freud's and Schopenhauer's theories. It is rather an attempt to prove and justify the existence of a group of problems which is founding and common to both thinkers: how to answer to the enigma of the body and what are its ethical implications? Our goal is therefore to investigate the body and the ethical consequences from the approach of this object by our authors. The body is not just an object of science, but holds an irreducible dimension of men. We chose to link body concepts in the two authors throughout the text, pointing out some similarities and differences that allow us to explain the ethical status of this object in the work of the philosopher and the psychoanalyst.

Keywords: Schopenahuer; Methaphysis of the Will; Freud; Metapsychology; body; compassion ethics.

Vivemos em uma época na qual o corpo ganha imensa importância cultural: por um lado, com o avanço da genética, das neurociências e da biologia molecular, o corpo é visto como um objeto físico ou como uma máquina, embora extremamente complexa e, por outro lado, ele é enaltecido como uma imagem de prazer, de beleza e de sucesso social. Sigmund Freud (1856-1939) era um médico e partilhava das concepções materialistas e cientificistas da medicina de sua época. No entanto, a experiência clínica o levou a se distanciar dessas concepções e a descobrir o corpo como encarnação de um sujeito, atravessado por imagens, afetos, memórias e linguagens. Apesar de seu ponto de partida materialista, Freud descobriu, por meio de sua conceituação metapsicológica, o corpo como representação. Ao ler o filósofo Arthur Schopenhauer (1788-1860), encontramos, na ideia basilar do "mundo como representação", a expressão filosófica dessa descoberta. Aquilo que Freud só alcançou lentamente foi formulado pelo filósofo, que partiu do idealismo kantiano. Essa pista nos ajudou a ler Freud tomando distância do fisicalismo, não só típico de sua mentalidade médica, mas que ainda hoje é a concepção dominante. O que significa, em termos psicanalíticos, a ideia do corpo como representação? Significa que o corpo não é apenas um objeto físico, porque está intimamente entrelaçado com a história fantasmática do sujeito. Uma história que não se confunde com a de um Eu consciente e senhor de si mesmo, porque é marcada pelo limite que a constitui como história de um sujeito padecente. Por conseguinte, a "corpolatria" contemporânea, a transformação do corpo como imagem de prazer e sucesso, é uma lastimável ilusão. Uma ilusão narcísica 
que desconsidera que o corpo é também o palco de uma luta sem tréguas, a luta entre as pulsões de vida e de morte. Essa outra descoberta freudiana ganha um novo alcance filosófico por intermédio da intuição schopenhaueriana da metafísica da vontade. O nosso objetivo é o de justificar a existência de um ponto de convergência entre os dois autores: uma concepção ética que, mesmo sendo distinta, implica o corpo e um tratamento do sofrimento humano. Ainda que trilhem caminhos distintos, o filósofo e o psicanalista acabam se encontrando na maneira como abordam o corpo e isso tem consequências para o modo como pensam a ética. ${ }^{2}$

Tomamos a problemática do sujeito encarnado e padecente como fio condutor não para comparar genericamente as duas obras, mas para trazer à luz algumas significações filosóficas da psicanálise, que poderiam ficar ocultas. É importante observarmos que, ao nos referirmos à ética, tanto no pensamento de Schopenhauer como no de Freud, temos em mente uma experiência que pode ser vivida pelo sujeito no fenômeno de compaixão e em um tratamento psicanalítico. Portanto, não utilizamos o conceito de ética como sendo um conjunto de normas e de regras que regem a vida humana, mas, ao contrário, nos debruçamos sobre a dimensão prática da ética, que enfatiza, justamente, o aspecto da experiência, que é vivenciada por um sujeito e que tem um efeito de cuidado com os aspectos mais íntimos de seu ser.

Longe de pretender esgotar a problemática que envolve a aproximação do filósofo com o psicanalista, entendemos que nossa investigação pode contribuir com esse debate. Mais especificamente, pode nos ajudar a corrigir certo déficit filosófico da psicanálise freudiana, ao buscar elucidar o significado ético da teoria metapsicológica. A metafísica da vontade pode ser encarada, sob esse ponto de vista, como sendo uma tentativa de responder à pergunta sobre o que é o corpo, tanto no interior da filosofia schopenhaueriana como no pensamento de Freud. Assim, segundo Paul-Laurent Assoun (1978), a referência metafísica "fornece a síntese antecipada intuitivamente, tornando possível a intelecção da verdade pulsional" (ASSOUN, 1978, p. 130). Dessa maneira, a intuição metafísica schopenhaueriana, que desvela a condição do corpo como sendo uma manifestação direta da vontade, funciona como uma passagem que abre os caminhos para a explicação psicanalítica, permitindo a coleta dos fatos da vida cotidiana, que implicam o corpo, fazendo sofrer os sujeitos que o habitam. A metafísica não fornece uma explicação fechada, mas, em vez disso, precipita, em termos formais, por meio de uma justificação teórica de fundo, o que será realizado pela explicação metapsicológica de Freud. Para exemplificar esse aspecto, lembremo-nos da função de elementos como os sintomas conversivos dos pacientes histéricos, da teoria da sexualidade e da teoria das pulsões na apreensão metapsicológica do corpo. A teoria filosófica de Schopenhauer, principalmente sua metafísica da vontade, "ao sistematizar o vivido pulsional, permite-nos objetivá-lo, portanto, pensá-lo" (ASSOUN, 1978, p. 132). Dessa maneira, Schopenhauer antecipa a psicanálise freudiana e, concomitantemente, coloca-nos na direção da construção de uma teoria ética em Freud.

Ao traçar o percurso metapsicológico do corpo, partindo do biológico até o pulsional, Freud tenta superar a condição de enigma desse objeto. O corpo é o depositário dos sofrimentos do sujeito, servindo como local para as tentativas de simbolização do mal-estar inerente às nossas relações com a pulsão e com a cultura. Contudo, a postulação do conceito de pulsão de morte coloca um impasse para Freud: nem tudo se resolve sob a lógica do princípio de prazer-desprazer; há algo de inapreensível do humano que sempre escapa, tal como demonstrou Schopenhauer com o conceito de vontade. A pulsão de morte, entendida como o que resiste às tentativas de integração psíquica, produz um excesso pulsional que transborda no e pelo corpo. As tentativas freudianas de apreensão da pulsão de morte, a interpretação biologista que é conferida pela suposição da existência de um caráter conservador que lhe é subjacente, caráter esse inerente a toda pulsão e funcionando como uma tentativa de retorno a alguma suposta ordem inorgânica, pode servir como modelo para pensarmos em certa precariedade de uma teoria metafísica em Freud. A partir daí, podemos pensar na existência de um déficit filosófico em sua obra, que é encoberto 
pela biologia especulativa, tal como vemos a partir das tentativas de elucidação da gênese da pulsão de morte. Assim, mesmo depois de anos de pesquisas metapsicológicas, o corpo, visto como o palco de expressão das relações do homem com as pulsões, não perde sua condição problemática, sempre colocando Freud a trabalho. ${ }^{3}$

Um processo análogo ocorre com a filosofia de Schopenhauer. Iniciando seu percurso a partir de Kant, nosso filósofo exalta a ciência de seu tempo, mas não endossa o materialismo subjacente a esta. $\mathrm{O}$ fato de ele não aceitar o idealismo absoluto hegeliano, e nem uma filosofia otimista da história, faz com que seu pensamento desemboque, sobretudo, em uma espécie de idealismo desencantado, no qual o corpo, na condição de sustentáculo do sujeito de conhecimento, mostra uma dimensão antropológica irredutível do homem. Afinal, é porque tem um corpo que o sujeito de conhecimento se torna um indivíduo encarnado, e isso exibe, justamente, a impossibilidade de uma plena reconciliação histórica do homem consigo mesmo, por meio da realização de ideais racionais e científicos que diriam, de uma vez por todas, o que é o indivíduo humano. $O$ realce à condição do corpo em sua teoria epistemológica afasta Schopenhauer de uma vez por todas de Kant, mas é na metafísica da vontade que encontramos a solução para seu idealismo. ${ }^{4}$

Neste sentido, como ocorre em Freud, o nosso filósofo precisa dar conta do significado do corpo, dentro de seu sistema de pensamento, adequando sua teoria a esse aspecto, que ultrapassa qualquer idealismo e, em maior medida, o fato de o sujeito de conhecimento ser um indivíduo encarnado pela vontade. Logo, o problema do conhecimento não se resolve no campo da representação, uma vez que, na condição de indivíduo, o sujeito de conhecimento tem um acesso imediato à vontade. É, justamente, essa relação especial do sujeito de conhecimento com o corpo que, ao mesmo tempo, diferencia o idealismo de Schopenhauer da concepção kantiana e impõe um limite ao idealismo do próprio Schopenhauer. Isso se justifica à medida que, tendo uma relação imediata com a vontade, o indivíduo tem acesso à outra maneira de conhecer, que não passa pela representação, mas é, ao contrário, imediata e direta e, por isso, mais clara e incontestável. A questão é que, para um entendimento mais claro desse outro modo de conhecimento, do qual o corpo é condição de possibilidade e testemunha, Schopenhauer precisa lançar mão de uma teoria metafísica, que sirva de sustentação a tal conhecimento sem a presença da representação. Daí a aparência de desencantamento de sua teoria epistemológica. Enfim, o problema do conhecimento necessita de uma base metafísica para ser mais bem esclarecido.

Se, por um lado, Schopenhauer vai além do idealismo, por outro, a primazia que confere aos aspectos da relação do corpo com a vontade faz com que ele também rejeite qualquer tipo de materialismo. A realidade empírica do corpo não é a que prevalece, mas sim sua condição de objetidade da vontade. É essa qualidade que tira o corpo da condição meramente material, tornando-o a expressão mais imediata do móbil do mundo. As consequências desse modo de apreensão do corpo são significativas para a filosofia schopenhaueriana, tanto no aspecto metafísico como no ético. O primeiro ponto que devemos ressaltar, e aqui cabe uma aproximação com a teoria metapsicológica de Freud, é o fato de nosso filósofo precisar instituir uma teoria metafísica para desvendar o enigma do corpo, o que permite inferirmos que ambos tomam esse objeto como ponto de partida de suas teorias. Schopenhauer cunhou uma teoria metafísica para solucionar o problema, enquanto Freud desenvolveu sua metapsicologia.

Mais uma vez, é por meio do sentido que ambos conferem ao corpo que se consolida a semelhança entre eles: se, em Schopenhauer, o corpo mostra o limite ao idealismo e ao materialismo, por meio da experiência imediata que temos da vontade, por outro, na perspectiva de Freud, que não parte do idealismo, mas de uma espécie de materialismo biológico, o corpo também é um limite. O corpo das histéricas, que Freud observa por meio de sua clínica como médico neurologista, subverte todo o seu modo inicial de pensar, modo esse pautado na tradição fisicalista alemã. É, pois, a partir da condição enigmática do 
corpo que o psicanalista se viu forçado a desenvolver uma teoria para dar conta dos fenômenos corporais embaraçosos com os quais se deparava. Tais desdobramentos teóricos desembocam na metapsicologia psicanalítica. Com Schopenhauer algo similar acontece, uma vez que o filósofo se viu obrigado a desenvolver uma teoria metafísica para dar conta do caráter paradoxal do corpo, que ultrapassa os limites da representação.

Ainda sobre o papel relevante do corpo nessa "passagem" do idealismo à metafísica da vontade na teoria schopenhaueriana, os comentários de Christopher Janaway (2007) merecem nossa atenção. Segundo esse autor, no mundo como representação, há, necessariamente, um sujeito que representa objetos, mas tal sujeito é "um olho que não pode ver a si mesmo", uma vez que o sujeito não pode ser objeto para si próprio e não está submetido ao espaço, ao tempo ou à lei da causalidade. Ora, apesar de Schopenhauer não utilizar esse termo, conforme ressalta Janaway, conhecemos esse sujeito como o sujeito transcendental de Kant. Contudo, no parágrafo dezoito do livro II de $O$ mundo, Schopenhauer confronta esse sujeito transcendental kantiano - o puro sujeito de conhecimento - com o fato de que cada sujeito humano, individualmente, está enraizado em uma realidade material por meio do conhecimento íntimo que tem de seu corpo (JANAWAY, 2007, p. 1-17). Assim, conforme Janaway salienta: "Conheço-me imediatamente como vontade incorporada, e não fosse eu capaz disso, permaneceria um puro sujeito isolado e fantasmagórico, que não compreendeu nada de sua essência íntima no mundo de sua experiência" (JANAWAY, 2007, p. 8. Grifos nossos).

Este autor afirma que é por meio dessa noção da vontade como a essência íntima do indivíduo, e que é conhecida pela ação corporal, que Schopenhauer estende o conceito de vontade. Logo, o corpo inteiro é vontade. Nele, esta última se manifesta assegurando o sentido derradeiro do organismo. O corpo, e cada parte e função dentro dele, é, pois, uma expressão da vontade de vida (JANAWAY, 2007, p. 8-9). Aí, por analogia, Schopenhauer pode, finalmente, sugerir que o mundo inteiro também é vontade.

Tais explanações nos permitem inferir que, primeiramente, o corpo, ou melhor, a experiência (conhecimento) imediata que temos dele, é o ponto de partida para o conhecimento que podemos ter do restante do mundo como representação. Em segundo lugar, afirmamos que o princípio de individuação não vale para o conhecimento que temos da vontade, por meio da experiência de nosso corpo, já que ela (vontade) está fora do tempo e do espaço, sendo, desse modo, eterna e imutável, tal como ressaltam o próprio Schopenhauer e o comentador, Janaway.

Por sua vez, Jair Barboza (2005), ao analisar os aspectos relativos ao modo particular de Schopenhauer se referir à vontade em termos metafísicos, ressalta o neologismo do filósofo para dar conta da relação especial da vontade com o corpo e com o restante do mundo fenomênico: objetidade (Objektität). Segundo o tradutor de $O$ mundo, objetividade, é um termo inadequado para traduzir esse vocábulo alemão, já que despreza o "caráter inconsciente de imediatez do ato da vontade, anterior ao tornar-se fenômeno consciente na intuição do entendimento" (BARBOZA, 2005, p. 157). ${ }^{5}$ É justamente esse o aspecto da metafísica da vontade que estamos salientando aqui.

Apenas em nossa razão, portanto, em um ato reflexivo, é que o nosso querer e o nosso agir se diferenciam. Efetivamente, são uma única e mesma coisa. Nesta medida, como sustenta Schopenhauer:

Todo ato verdadeiro, autêntico, imediato da vontade é também simultânea e imediatamente ato fenomênico do corpo; $\mathrm{e}$, em correspondência, toda ação sobre o corpo é também simultânea e imediatamente ação sobre a vontade, que enquanto tal se chama dor, caso a contrarie, ou bem-estar, prazer, caso lhe seja conforme (SCHOPENHAUER, 1819, p. 158. Grifos nossos). 
O corpo sofre, assim, os efeitos da vontade da mesma maneira que, com Freud, vemos esse mesmo corpo sendo atravessado pelos efeitos da pulsão, sempre traumáticos, independentemente de serem entendidos como finalidades de prazer ou de dor. Para Schopenhauer, essas duas sensações não são meras representações, mas afecções imediatas da vontade em seu fenômeno - o corpo. Logo, o prazer e a dor se distanciam de algumas poucas afecções consideradas imediatamente como meras representações, que não estimulam a vontade, e por meio das quais o corpo é visto como um mero objeto imediato do conhecimento: as afecções dos órgãos dos sentidos, como a visão, a audição e o tato. Estas últimas não afetam a vontade diretamente, segundo nosso filósofo, por se constituírem um estímulo muito fraco para nossa sensibilidade, já que apenas fornecem os primeiros dados de onde deriva nossa intuição:

Toda outra afecção mais forte ou diferente daqueles órgãos do sentido já é dolorida, ou seja, contraria a vontade, a cuja objetidade também pertencem. - A fraqueza dos nervos se revela no fato de que as impressões, que deveriam ter apenas o grau de força suficiente para torná-las dados do entendimento, atingem o grau mais elevado e movimentam a vontade, ou seja, estimulam dor ou sentimento de bem-estar, embora o mais das vezes dor, que no entanto é em parte abafada e insignificante. Nesse caso, tons isolados e luz intensa não apenas são sentidos dolorosamente, mas em geral também ocasionam disposição hipocondríaca aguda (SCHOPENHAUER, 1819, p. 158. Grifos nossos).

Em nossa opinião, tais afirmações de Schopenhauer atestam a relação intrínseca e imediata do corpo com a vontade, servindo o primeiro como um local privilegiado de acesso para a última. A vontade toma $\mathrm{o}$ corpo totalmente, dando-se a ver, ou se objetivando por meio da dor, conforme o filósofo descreve. Além disso, essas declarações de Schopenhauer são muito próximas às conclusões de Freud, quando este se refere aos efeitos da dor e de alguns fenômenos hipocondríacos que tomam o corpo de maneira imediata. ${ }^{6}$ Logo, mais uma vez, constatamos uma semelhança entre os dois autores no tratamento e na significação do corpo.

Os desdobramentos advindos da metafísica da vontade e da metapsicologia freudiana seguem caminhos distintos, mas, apesar disso, podemos realçar outro ponto de convergência interessante, referido ao modo como os dois autores tratam a questão da realidade, e que também impacta o modo como ambos entendem o corpo. Para Schopenhauer, o mundo pode ser visto tanto na perspectiva da representação como na da vontade. Temos, a partir daí, dois modos de apreensão possíveis da realidade. O filósofo privilegia o acesso imediato que temos ao sentido do mundo como vontade, por meio da relação que temos com o nosso corpo próprio. É isso que lhe permite, via analogia, estender o conhecimento que nosso corpo fornece ao restante do mundo e concluir que tudo no mundo é vontade, variando apenas os graus de sua objetivação, conforme já ressaltamos. Logo, a realidade que interessa a Schopenhauer é a dada pela vontade, sendo o corpo um componente necessário para esse outro modo de conhecimento do mundo. Com Freud, algo equivalente acontece, à medida que ele enfatiza a realidade do Inconsciente, que denominamos realidade psíquica, e que é exemplificada por meio do simbolismo, presente nos sintomas conversivos dos histéricos e nos sonhos. Também em Freud vemos, pois, o papel central do corpo no processo de constituição da realidade, que é fantasmática e que faz do elemento corpóreo um palco para a expressão do Inconsciente, por meio dos efeitos nele (corpo) da pulsão. Tais aspectos chamam nossa atenção para a presença e a prevalência, em ambos, de outra realidade no ser humano que ultrapassa a racionalidade da representação consciente e que, além disso, tem o corpo como testemunha direta de suas manifestações. Ambos são, neste sentido, críticos da razão iluminista e da cultura prevalentes na segunda metade do século XIX, expressando um modo de inteligibilidade do homem e da cultura inspirado em ideais românticos. Por meio, então, desses modos particulares de conceber o homem, algo de irredutível toma corpo no corpo dos sujeitos, tanto na filosofia de Schopenhauer como na psicanálise freudiana. Isso não é sem consequências para o campo da ética. 
Entendemos que o percurso que liga a teoria do conhecimento à ética, pela via da metafísica, é mais explícito na filosofia de Schopenhauer do que na metapsicologia. Nisso não há nenhum demérito de Freud, somente uma visada teórica diferente, ou seja, uma preocupação clínica que não existe para Schopenhauer. No pensamento freudiano, tal inquietação com o sofrimento dos pacientes permite dizermos da existência de uma preocupação ética, funcionando como um dos pilares de seus desdobramentos teóricos desde o início de sua produção clínica e teórica. Sua preocupação com as questões da técnica dá provas disso. Contudo, Schopenhauer mostra a ligação da metafísica com a ética de forma mais evidente. Sua metafisica da vontade confere um sentido ao corpo que é, em certa medida, comprovado pela clínica e pela metapsicologia freudianas.

Mais uma vez, há uma aproximação possível entre o filósofo e o psicanalista, por meio do modo como ambos pensam as relações entre o Eu e o corpo. Há duas concepções possíveis do Eu no pensamento de Schopenhauer: o Eu pode ser identificado ao sujeito de conhecimento, sob a perspectiva da representação e, no tocante ao mundo visto como vontade, esse mesmo Eu é um sujeito de vontade ou a manifestação corporal da vontade de vida. Nosso filósofo chega a invocar o termo "milagre" para tentar contornar o fato estranho da existência de uma confluência, no Eu, entre o sujeito de conhecimento e o sujeito do querer. Mas é na relação que o Eu estabelece com o corpo que podemos encontrar uma saída para o embaraço, embaraço esse que marca as tentativas de Schopenhauer de responder à antiga questão acerca do que é o homem. A doutrina da identidade do corpo com a vontade é sua tentativa de resposta. Logo, é a vontade que - como aquilo que move o Eu, o corpo e o restante dos objetos do mundo - faz com que possamos ter consciência, por meio de nossas ações corporais, do fato de que tudo no mundo é expressão de uma mesma e única vontade, inclusive o Eu. Este é, pois, um organismo corporificado pela vontade. Nesse sentido, o corpo que interessa destacarmos, na acepção de Schopenhauer, independe do princípio de razão suficiente, revelando, como ressalta Jair Barboza (2005), "um amplo espectro de atos volitivos [...] que não são representações, não são um conceito ou saber, mas devem ser compreendidos sob rubricas bem diferentes, como 'dor', 'prazer', 'volúpia' etc.' (BARBOZA, 2005, p. 107).

Em Freud, o Eu também é eminentemente corporal, no sentido de que é por meio da relação entre esses dois, percebida inicialmente como uma Gestalt, que um Eu pode vir a se desenvolver e, também, ter condições de se perceber como uma unidade psíquica integrada. $O$ corpo funciona, então, como uma superfície de onde se originam sensações externas e internas, operando o que podemos chamar de autorrepresentação do Eu. Portanto, de acordo com a psicanálise freudiana, o Eu se define por um efeito projetivo, a partir de sua relação com o corpo, relação essa que, assim como afirma Barboza, desperta, no próprio corpo, uma vasta gama de fenômenos. Por sua vez, tais afecções são o que tornam o objeto corpóreo um local privilegiado para as manifestações simbólicas, ou não, da pulsão, alçando-o ao papel de depositário do sofrimento dos sujeitos. Freud se ocupou dessas questões, desde o início de sua construção metapsicológica. O psicanalista sempre esteve atento a esse papel do corpo na vida de seus pacientes, buscando alternativas - pela articulação sempre próxima da clínica com a teoria, atestada pela técnica - para decifrar os sintomas e, desse modo, alterar a relação do sujeito com seu corpo e com o mundo que o cerca. ${ }^{7}$

Essa perspectiva de cuidado com o outro está presente no pensamento de Freud desde os tempos do Projeto para uma psicologia científica (1895) e atravessa toda a sua obra, permitindo-nos sustentar a existência de uma preocupação ética de base nos estudos freudianos. Em 1895, quando está às voltas com o problema da concepção de um aparelho psíquico, podemos depreender uma questão ética como parte integrante de suas preocupações, já que postula um aparelho mental que tem como objetivo o tratamento das excitações, oriundas do mundo externo e do próprio corpo dos sujeitos. Assim, o tratamento psicanalítico, tal como é concebido desde esses tempos ancestrais, leva em conta certa quota de transformação de afetos, possibilitando, pois, a passagem da miséria neurótica, ou histérica, para uma infelicidade 
comum. No artigo "Análise terminável e interminável”, de 1937, a inquietação de Freud, com o aspecto ético, permanece e pode ser evidenciada pelo modo através do qual o psicanalista delimita a tarefa de um trabalho analítico: "a experiência nos ensinou que a terapia psicanalítica - a libertação de alguém de seus sintomas, inibições e anormalidades de caráter neurótico - é um assunto que consome tempo" (FREUD, 1937a, p. 219).

O ponto de vista dos dois autores converge, novamente e de maneira mais contundente, no tratamento que ambos dão ao corpo nos aspectos relacionados à ética, fazendo com que as questões relativas ao egoísmo e à experiência mereçam nossa atenção. Schopenhauer se ocupa das questões éticas propondo uma saída ascética para o sofrimento do homem no mundo. O filósofo deixa claro que o caminho da experiência é o único capaz de fundamentar a moral, e a experiência em questão é a da compaixão. Somente ela é capaz de mover o homem no campo da ética. Antes, contudo, de se dedicar à experiência da compaixão em termos puramente éticos, Schopenhauer privilegia o campo da experiência, no âmbito de sua teoria metafísica. Sob esse aspecto, a experiência é vista como sendo o modo de acesso à essência do mundo - a vontade - e, mais uma vez, o corpo tem participação imediata aí, já que é por meio dele que tal experiência é vivida. Somente a posteriori é que percebemos que não somos livres, que estamos submetidos à necessidade da vontade. É, pois, no "campo do vivido", o das experiências cotidianas, que nos damos conta das incidências da vontade em nosso corpo. Apesar de todos os nossos propósitos e reflexões, não mudamos o rumo de nossa conduta, repetimos, do início ao fim de nossas vidas, o mesmo caráter até cumprirmos nosso "destino".

Tais afirmativas de Schopenhauer soam "familiarmente estranhas" às descrições freudianas, acerca do caráter compulsivo da pulsão de morte, caráter que faz o sujeito repetir algo que lhe causa mal-estar sem nenhuma possibilidade de escolha. A saída que Freud propõe para esse tipo de sofrimento humano, que também afeta o corpo diretamente, através de manifestações de angústia e dor, é a fornecida pela escuta analítica. É, desse modo, por meio da experiência clínica de uma psicanálise que um sujeito pode deixar que seu corpo sofrido participe da conversa, como ocorreu com a paciente de Freud, a Srta. Elisabeth von R., e que, a partir de um cuidado ético do psicanalista, por meio da escuta, consiga perceber, nessa conversa, os meandros que delinearam seu sofrimento, ressignificando-os e, com isso, possa transformar a condição do corpo de depositário de sofrimentos em "nau do desejo", ou simplesmente em um veículo rumo à novidade. Tudo isso, obviamente, é parte integrante de um processo que supõe a superação das fantasias constitutivas do Eu, permitindo ao sujeito em tratamento dirigir um olhar menos egoísta e mais humilde para si mesmo e para seus semelhantes. Contudo, pode ser que, com alguns sujeitos, as coisas tomem rumos diferentes e o processo psicanalítico tenha que se haver com forças pulsionais mais demoníacas em ação. Quando isso ocorre, constatamos a presença de um tipo de arranjo pulsional em que os efeitos da pulsão de morte são mais devastadores, dificultando o percurso do sujeito e, consequentemente, a mudança da condição de seu corpo. Nesses casos, a escuta ética, por parte do psicanalista, pode não ser suficiente, deixando o sujeito desamparado e à mercê dos efeitos nocivos e excessivos da pulsão de morte. $^{8}$

Tanto na filosofia de Schopenhauer como na psicanálise de Freud, existe uma proposta de acesso à verdade por meio da experiência, uma experiência que implica o corpo espontaneamente e de maneira imediata, mesmo que essa experiência seja concebida de modos distintos pelo filósofo e pelo psicanalista. Afinal, a experiência da compaixão e a de uma psicanálise é uma experiência de corpo - como carne -, ou seja, de um corpo encarnado pela vontade ou pela pulsão. O filósofo e o psicanalista se aproximam, então, ao falarem de uma experiência que tem valor de verdade e que, além disso, envolve uma dimensão de perda dos ideais do eu. Nesse sentido, não se trata, em ambos, de uma verdade nos moldes de uma adequação do sujeito às leis do mundo racional, mas, ao contrário, de algo que é desvelado, por meio da 
experiência. Tal verdade mostra-nos, ainda, o limite, isto é, nossa condição de sujeitos finitos. É por isso, justamente, que tanto o filósofo como o psicanalista são críticos da cultura vigente ao final do século XIX.

Em Schopenhauer, o aspecto vivencial da verdade fica mais evidente por meio do caráter libertador que o exercício da compaixão contempla, possibilitando um acesso à ascese ou à negação da vontade de vida $\mathrm{e}$ do corpo próprio. No âmbito da psicanálise freudiana, algo similar pode ser experimentado pelo analisante, por meio dos efeitos das construções em um tratamento analítico. A partir da leitura de "Construções em análise” (1937), podemos afirmar, ao lado de Freud, que a eficácia de uma construção jaz, exatamente, no fato de que há uma recuperação de uma experiência perdida, desvelando-se um elemento da verdade histórica do sujeito. Em nossa opinião, a partir disso, podemos alegar que o psicanalista vienense, assim como o filósofo, realça o caráter passivo da experiência, isto é, a experiência é da ordem do sofrimento; é vivida pelo sujeito no e com seu corpo, revelando a dimensão de pathos do humano (FREUD, 1937b, p. 169-170).

Outro ponto que merece nossa atenção se refere ao caráter transformador, que tanto a experiência da psicanálise como a da compaixão contempla. Dizemos que algo da dimensão do indizível, ou do irredutível, de nossa condição de sujeitos padecentes, tem a possibilidade de ser tocado e, por que não, trabalhado em ambas as experiências. Novamente, o filósofo e o psicanalista caminham muito próximos, uma vez que as experiências da compaixão e a psicanalítica permitem ao sujeito uma transformação do Eu, uma travessia do egoísmo e dos ideais, que tanto sofrimento causam ao homem. Tais ideias corroboram nossa hipótese inicial, aproximando Schopenhauer de Freud, por meio do modo como pensam o corpo e a ética, mesmo que os desdobramentos de seus pontos de vista apontem para caminhos diferentes. ${ }^{9}$

A perspectiva ética de Schopenhauer, que engloba a experiência de compaixão, pressupõe uma anulação do egoísmo e da própria vontade individual de um sujeito, em prol da diminuição do sofrimento de outro ser humano. Dessa maneira, o filósofo institui uma teoria ética, que é diametralmente oposta à indicada por seu antecessor e mestre, Kant, implicando a necessidade de colocarmos a razão a serviço da vontade. Somente isso faz com que o bem-estar alheio se torne nosso motivo para agir, permitindo, pois, uma identificação com nosso semelhante que sofre. Tudo isso, obviamente, se deve ao conhecimento que temos de nosso semelhante, conhecimento que é imediato e direto, dado pela vontade. Percebendo, então, que tanto nós como nosso semelhante somos meras manifestações da vontade, toda diferença que nos separa dos outros se anula, dando lugar ao fenômeno da compaixão. De acordo com Schopenhauer, "este processo é digno de espanto e até misterioso" (SCHOPENHAUER, 1841, p. 136), uma vez que a razão ou o conhecimento racional não podem explicá-lo. Apenas a especulação metafísica pode dar conta disso. É, pois, na metafísica que encontramos a chave para nosso entendimento da ética da compaixão.

Novamente, a questão da experiência entra em cena. Segundo o filósofo, o campo das ações humanas é aquele em que a compaixão se mostra de maneira mais efetiva, assim como seu oposto, a maldade. $\mathrm{O}$ indivíduo, no qual a diferença entre seu Eu e o outro se mostra absoluta, executa atos egoístas, do mesmo modo que acontece com quem desconsidera o outro em proveito próprio. No entanto, ao agirmos compassivamente, ajudamos o outro sem nenhum motivo egoísta de nossa parte. Entendemos que o corpo está implicado no processo ético, conforme Schopenhauer, desde sempre, já que agimos, necessariamente, como sujeitos encarnados. Afinal, somos nós, expressando a vontade que nos habita, quem fazemos ou deixamos de fazer algo bom para nosso semelhante. Agimos eticamente com nossos corpos, pois estes já são uma expressão da vontade.

Todos esses aspectos que relacionam o corpo com a experiência ética da compaixão atestam a participação imediata e direta da dimensão corporal na filosofia de Schopenhauer. Contudo, a questão do papel do corpo no sofrimento dos sujeitos também merece destaque. Schopenhauer define o sofrimento como 
sendo causado pela luta da vontade consigo mesma, em seu processo de objetivação no indivíduo e no mundo. Na medida em que o fenômeno da vontade se aperfeiçoa, o sofrimento se torna mais manifesto. O corpo testemunha esse fato diretamente, uma vez que não há corpo sem apetite ou esforço, isto é, vemos nosso corpo sempre querendo algo ou ansiando por alguma satisfação. Segundo Schopenhauer, à medida que a vontade se objetiva, a consciência se eleva e o nosso tormento aumenta, alcançando o ápice no homem, quanto mais inteligente ele é. A existência humana é, desse modo, o destino secreto e essencial da vontade, e a vida de nosso corpo não passa de um morrer ininterruptamente evitado, uma morte adiada, já que a base de todo querer é sempre a carência e a necessidade. Nossa vida oscila entre a dor e o tédio, componentes básicos de nosso viver, de acordo com o filósofo, sendo o nosso corpo o palco para as manifestações de nossos sofrimentos.

Não há como deixarmos de salientar o quão próximas das assertivas freudianas estão essas afirmações de Schopenhauer. Ao ouvirmos o filósofo falar sobre os aspectos relativos ao conflito da vontade consigo mesma, temos a impressão de estarmos lendo os desdobramentos freudianos advindos da postulação do segundo dualismo pulsional - que descreve o conflito psíquico como ocorrendo entre as pulsões de vida em oposição à pulsão de morte - em Além do princípio de prazer (1920). Logo, da mesma maneira que a vontade se afirma no mundo à revelia do sujeito humano, produzindo efeitos em seu corpo, também a pulsão de morte não deixa alternativas ao sujeito, que vivencia seus efeitos excessivos no corpo, que ultrapassam a possibilidade de escolha racional.

Tal proximidade permite falarmos da dimensão humana como pathos, que se dá a ver tanto em Schopenhauer como em Freud. Essa dimensão considera o corpo como o local privilegiado para as manifestações do sofrimento humano. Em ambos, vemos, pois, a necessidade de um ultrapassamento da condição patológica do corpo, no percurso ético de um sujeito, seja por meio de um processo psicanalítico - no qual os fenômenos narcísicos e os sintomas corporais necessitam, em alguma medida, ser superados -, seja , como propõe Schopenhauer, pelo conhecimento, que permite o fenômeno da compaixão, em que também há a necessidade de refrearmos a afirmação constante da vontade, via supressão das diferenças entre um querer e outro e que implica o corpo diretamente. À medida que seu corpo afirmar a vontade, o homem está fadado ao sofrimento. A diferença, com relação à concepção freudiana, se apresenta, porém, no fato de que, para Schopenhauer, a possibilidade de se livrar do sofrimento aponta para uma negação da vontade, via compaixão ou ascese, ${ }^{10}$ e, na perspectiva de Freud, o processo psicanalítico se oferece como uma possibilidade, não de alcançar uma vida plena e feliz, mas de um autoconhecimento que pode esgotar certa quota de sofrimento. Entretanto, não há nenhuma garantia prévia de que isso acontecerá em uma psicanálise. Afinal, a pulsão não se esgota, e o Inconsciente é dinâmico, ou seja, continua produzindo efeitos enquanto há vida, inclusive nos sujeitos que se submeteram a um processo psicanalítico.

Para Schopenhauer, a afirmação da vontade e a afirmação do corpo são sinônimas, sendo a veemência do impulso sexual a mais decidida expressão da vontade de vida. Daí advém o fato de a vida ser sofrimento, uma vez que o mundo, como fenômeno da vontade, é como é e a vontade afirma-se a si mesma nesse mundo incessantemente. $\mathrm{O}$ conflito interno da vontade consigo mesma tem seu ponto de partida no egoísmo, a partir do fato de cada indivíduo toma a si mesmo como centro do universo, alçando ao primeiro plano sua própria existência e seu bem-estar. Contudo, Schopenhauer entende ser possível o caminho da negação da vontade e, de acordo com seu ponto de vista, esse percurso começa pelo corpo. Considera que a renúncia voluntária à satisfação do impulso sexual é uma manifestação da negação da vontade, por se tratar aí de uma autossupressão voluntária do querer individual, por meio da entrada em cena de um conhecimento que age como um quietivo para a vontade. Nesse sentido, "a negação do próprio corpo já se expõe como uma contradição da vontade com seu fenômeno” (SCHOPENHAUER, 1819, p. 428). 
A partir de tais considerações, o filósofo define os conceitos de justiça e injustiça, de acordo com a relação desses com o corpo. Sua acepção de justiça é negativa e derivada, uma vez que a entendemos como sendo a negação da injustiça, manifestando-se por toda ação que não seja negação da vontade do outro em favor da afirmação da vontade própria. Por sua vez, a noção de injustiça é originária e positiva, pois deriva do egoísmo e da maldade, dois dos principais motivos do agir humano, de acordo com Schopenhauer. Há injustiça na medida em que a vontade de um indivíduo invade os limites da afirmação da vontade de outro ser humano, por meio da destruição ou do ferimento do corpo do outro ou, ainda, ao impelir as forças do outro a servirem sua vontade individual, em detrimento do serviço à vontade, que se manifesta no corpo do outro. Logo, "quem sofre injustiça sente a invasão na esfera de afirmação do próprio corpo, via negação deste por um indivíduo estranho, como uma dor imediata" (SCHOPENHAUER, 1819 , p. 429). Contrariamente, quem pratica um ato injusto sabe que, em si mesmo, é a manifestação da mesma vontade que se apresenta no corpo do outro, por isso, ao transgredir os limites do próprio corpo, torna-se uma expressão da negação da vontade. Tudo isso, segundo o filósofo, proclama o conflito da vontade consigo mesma que, dessa maneira, crava os dentes na própria carne. O corpo atua como uma testemunha direta dos atos de injustiça e de justiça, uma vez que vivencia tais ações, na forma de uma experiência corporal, como o próprio Schopenhauer sustenta, ao se referir à dor como uma consequência direta, no corpo, de um ato injusto. Portanto, sua teoria ética se ocupa do corpo de modo imediato, já que é por meio dele que as ações morais se efetivam.

Outro aspecto importante, na proposta ética de nosso filósofo, e que também engloba o corpo, refere-se ao atravessamento do princípio de individuação. Segundo observamos com Schopenhauer, há justiça quando conseguimos ver por intermédio desse princípio, suprimindo a diferença entre os indivíduos. Ir além do princípio de individuação é, neste sentido, o caminho necessário no processo de autoconhecimento da vontade e, consequentemente, em sua decisão de negar-se ou não. Assim, a visão através desse princípio torna possível o amor desinteressado e a compaixão pelo outro, fazendo com que o indivíduo perceba que tudo lhe é próximo; todos os tormentos que vê no mundo, todas as dores e o sofrimento alheio tocam-lhe o espírito como se fossem seus. O indivíduo conhece o todo do mundo, alcança seu ser e percebe esse mesmo mundo em um perecimento constante, num esforço vão e em um íntimo conflito. "O homem, então, atinge o estado de voluntária renúncia, resignação, verdadeira serenidade e completa destituição da vontade” (SCHOPENHAUER, 1819, p. 482). Novamente, o corpo está presente nesse processo, uma vez que tal aspecto implica uma decisão racional e voluntária de um indivíduo de não satisfazer os caprichos do impulso sexual, por exemplo. ${ }^{11}$

Schopenhauer sustenta, ainda, que negar a vontade significa ir contra os desejos intencionalmente, refreando a vontade de propósito. $\mathrm{O}$ indivíduo que assim procede mortifica, inclusive, o próprio corpo, impedindo que ele anime a vontade, da qual é espelho e expressão. Logo, a anulação da vontade no corpo incita práticas como o jejum, a castidade, a autopunição e o autoflagelo para, por meio de tais privações, anular e mortificar cada vez mais a vontade. ${ }^{12}$ Nesse sentido, nosso filósofo abre o caminho para pensarmos em um "corpo ascético", ou seja, um corpo que não mais espelha a afirmação da vontade de vida. Mas em que medida isso é possível $?^{13}$ Schopenhauer responde com base nos exemplos dos relatos das vidas dos santos e dos ascetas, ou seja, daqueles que, por meio de um enorme esforço ascético, neutralizaram o impulso cego de seu querer viver.

O que teria Freud a dizer disso? Entendemos que a ultrapassagem do princípio de individuação pode ser aproximada do propósito de um processo psicanalítico, desde que confrontemos tais aspectos sob a perspectiva da participação do egoísmo e do corpo. No pensamento de Freud, não há espaço para considerarmos a anulação do desejo sexual, já que esse sempre foi visto, desde $A$ interpretação de sonhos (1900), como aquilo está na base de nossa vida psíquica. Mas, por outro lado, existe, a partir da metapsicologia, 
uma abertura para apreciarmos o fato de que os aspectos narcísicos devem ser superados em uma experiência psicanalítica. Dessa maneira, se consideramos, com Schopenhauer, que, ao suprimir as diferenças entre os caracteres, o indivíduo percebe que é parte de uma única e mesma vontade, que atua em tudo no mundo, inclusive em seu corpo, através da negação do desejo sexual, transformando o corpo em um "corpo ascético", como no caso dos santos, poderemos, então, aproximar tais fatos do que ocorre com o corpo em uma experiência clínica. Podemos, desse modo, atestar a confluência das duas propostas éticas neste aspecto, que tem como resultado a alteração da condição do Eu e do corpo. Como lembra Schopenhauer: "pela participação diminuída do próprio eu, a preocupação angustiosa em relação ao mesmo é enfrentada e reduzida em sua raiz" (SCHOPENHAUER, 1819, p. 475).

Vemos, com Freud, que uma escuta ética, por parte de um psicanalista, pode proporcionar a mudança da condição do corpo de um sujeito, que se submete ao processo de análise. Processo esse que também implica, em certa medida, a anulação do Eu em prol da construção de uma nova subjetividade, na qual supomos que o corpo não representa mais um local de manifestação do sofrimento apenas, mas, ao invés disso, também pode servir como uma "nau para o desejo" do sujeito. Em nossa opinião, a teoria metapsicológica, que Freud cunhou para tentar dar conta do corpo e do sofrimento de seus pacientes, aponta para tal aspecto. É, pois, por meio da articulação constante, no seio da metapsicologia, entre a teoria e a clínica, que vemos convergir as preocupações freudianas com o corpo e a ética. Logo, do lado de Schopenhauer, temos um desejo que é negado e um "corpo ascético", ao passo que, sob a perspectiva de Freud, podemos pensar em uma afirmação do desejo, em um corpo liberto de adoecimento, mesmo que não tenhamos qualquer garantia de que essa condição corporal permanecerá e, se for o caso, por quanto tempo. ${ }^{14}$

Ainda com o intuito de aproximarmos Freud de Schopenhauer, por meio do modo como concebem o corpo e as implicações disso para a ética, podemos alegar que ambos não acreditam na bondade humana, ressaltando sempre a natureza maldosa inerente ao homem. Esse é, consequentemente, mais um aspecto do pathos, da condição humana, partilhado por eles. Apesar de ambos terem explicações distintas para essa característica humana, tais aspectos podem ajudar-nos a inseri-los em uma discussão atual, acerca das diferentes versões do mal-estar contemporâneo, que se dá a ver por meio das figuras da violência, da indiferença com relação ao sofrimento alheio e, ainda, do incremento de sintomas, sem possibilidades de simbolização, que afetam o corpo cada vez mais. Mesmo sendo o quadro das formas de mal-estar atual diferente do tempo de Schopenhauer e de Freud, o corpo continua presente, talvez não tanto em seu aspecto simbólico, mas como real. ${ }^{15}$ Como ressalta o psicanalista Joel Birman (2012), no lugar das velhas modalidades de sofrimentos, pautadas no conflito psíquico, em que os imperativos das pulsões e das interdições morais se opunham, vemos o mal-estar na atualidade se inscrever nos registros psíquicos do corpo, da ação e das intensidades. Neste sentido, o pensamento e a linguagem tendem a se diluir, como ordenadores do mal-estar na atualidade, já que a problemática em voga ultrapassa o registro da clínica psicanalítica. Na opinião de Birman, da qual partilhamos, o que vemos hoje, no registro clínico, é o ponto de chegada de um processo de mudança da subjetividade. Temos que ter isso em mente para não nos debruçarmos ingenuamente sobre a clínica.

Logo, não se trata de buscarmos uma apreensão totalizante da vida, seja pela via da ciência, ou pelo caminho fornecido pela farmacologia, como tentativa de nos vermos livres do mal-estar. Há algo em nossa constituição humana que escapa a toda e qualquer ordem adaptativa. Somos, pois, expressão de algo inexorável, que ultrapassa toda tentativa integradora. Schopenhauer e Freud denunciam essa nossa condição. Devemos, como psicanalistas, tal como ressalta o também psicanalista e filósofo Carlos Roberto Drawin (2006), propiciar aos nossos pacientes outros meios de lidar com seus sintomas, evitando, dessa maneira, a transformação da clínica psicanalítica em um tipo de adequação social ou em uma mera normalização de comportamentos. 
Com isso em mente, não precisamos enfatizar a prevalência da pulsão de vida ou de morte em determinado fenômeno. Quando salientamos a qualidade de "amálgama", como sendo a que caracteriza o entrelaçamento constante entre as pulsões de vida e de morte, podemos destacar, ao lado de Denise Maurano (1995), o caráter indomável no qual Freud sustenta a teoria das pulsões. Nesse sentido, dizemos que algo sempre escapa e isso que escapa utiliza-se do corpo como última tentativa de inscrição psíquica. Isso é válido para Schopenhauer também, tal como demostram as manifestações de afirmação da vontade de vida no corpo e no mundo.

A dimensão ética se faz presente, portanto, em uma escuta psicanalítica, desde que um analista tenha abertura psíquica suficiente para lidar com o inédito e com o inesperado do humano, independentemente da maneira como a pulsão se apresenta no corpo. Assim, a distância analítica, necessária em um processo analítico, não exclui o cuidado com o sujeito que sofre. O que a proposta ética de Schopenhauer tem de semelhante com tais ideias do pensamento freudiano - e isso vai além dos aspectos que aproximam e que diferenciam os conceitos de pulsão, em Freud, e de vontade, em Schopenhauer - é a existência de algo da ordem de uma "destituição do eu", na qual o egoísmo humano e suas pretensões totalizantes são ultrapassados nos processos éticos teorizados por ambos, implicando, necessariamente, o corpo nesse processo.

Lidar, assim, com o inesperado e com a dimensão do inapreensível, na relação do sujeito com a pulsão, faz parte da ética da psicanálise. ${ }^{16}$ Tais aspectos permitem afirmarmos que um processo psicanalítico, que viabiliza uma escuta ética do corpo, pode ser descrito como sendo uma busca pela verdade do sujeito e de seu desejo e, quando isso ocorre, uma quota de sofrimento é deixada de lado. Nosso corpo mostra-nos tais verdades, a do sintoma e a do desejo, basta-nos ter a coragem para "deixá-lo participar da conversa com um analista. ${ }^{17}$

Já a proposta schopenhaueriana para a felicidade, que também pode ser lida como sendo uma busca pela verdade, leva em conta a mortificação do corpo e da vontade de vida. Em os Aforismos para a sabedoria de vida (1851), o filósofo dá pistas da existência de uma alternativa otimista para nos libertarmos de nossa condição de sujeitos encarnados e, por isso, padecentes. Schopenhauer salienta que a felicidade possível está na aceitação daquilo que somos, e, mais uma vez, exemplifica seu ponto de vista citando as vidas do santo e do gênio. Entendemos que essas ideias do filósofo ratificam os aspectos relativos a um resultado possível em um processo de análise, nos moldes de Freud.

Podemos, então, sustentar que, tanto em Schopenhauer como em Freud, não há uma proposta de entendimento do mundo sistematicamente fechada, mas, ao contrário, ambos vislumbram uma abertura para a vida; ambos propõem uma saída para o pathos humano, que passa pela experiência do corpo, experiência esta que é, eminentemente, ética, mesmo que a experiência da compaixão e a experiência clínica de um processo psicanalítico sejam tão díspares. E, além disso, também acreditamos que Schopenhauer nos ajuda a compreender melhor as crenças cientificistas de Freud, por meio do tom pessimista que imprime a sua crítica à cultura. $\mathrm{O}$ que podemos dizer, então, diante de uma cultura que não crê mais no iluminismo? Nosso filósofo propõe minorarmos o sofrimento humano, via negação da vontade, à medida que consegue se desvincular da crença totalizante, apregoada pelos ideais ilustrados, com sua proposta metafísica.

Já Freud, por sua vez, mesmo sendo um crítico contumaz dos ideais culturais de seu tempo, como atestam suas formações em Moral sexual "civilizada" e doença nervosa moderna (1908) e em O mal-estar na civilização (1930), continua fiel a certo tipo de ilusão totalizante, muito marcado, em nossa opinião, pela formação científica e filosófica que obteve. Contudo, essa sua "ingenuidade metafísica" não consegue anular sua genialidade metapsicológica. Se a teoria psicanalítica permitiu o deciframento do corpo e da histeria, também não escapou a Freud o fato de que a histérica goza através do seu sintoma. É, justamente, sua atenção para com a repetição incessante do sintoma que demonstra a existência de uma preocupação 
ética com o sofrimento de seus pacientes, desde o início de seus escritos, funcionando como alicerce para a construção da teoria metapsicológica.

Dessa maneira, como ressalta o próprio Freud, mesmo que não possamos abolir todo o sofrer, podemos abolir parte dele, porém, não podemos esquecer-nos da natureza indomável de nossa própria constituição psíquica. Além disso, conforme a psicanalista Inês Loureiro (2014): "a postulação freudiana do inconsciente coloca em questão o próprio sujeito da experiência, tal como abordado, até aqui, pela tradição filosófica" (LOUREIRO, 2014, s/p). É, pois, o conceito de inconsciente que coloca Freud - este filho da modernidade $-{ }^{18}$ como um de seus maiores e mais severos críticos, mostrando que a vida psíquica não é regida pela razão, mas pelas pulsões. Novamente, delineia-se, a partir daí, a proximidade com a filosofia de Schopenhauer. Tanto no pensamento de um como no do outro, o desamparo surge como uma figura interessante para tentarmos abarcar o pathos do homem moderno. Diante, então, do fracasso do poder da razão em conferir inteligibilidade ao mundo da vida, resta-nos a dor, o sofrimento e o tédio, como demonstra a metafísica da vontade schopenhaueriana, ou, ainda, a cultura da pulsão de morte, como vemos com Freud.

Ao chamarmos a atenção para a dimensão ética do corpo, presente nas obras de Schopenhauer e de Freud, esperamos contribuir com o pensamento sobre o mal-estar na atualidade. Percebemos que ambas as propostas éticas, que levam em conta um tipo especial de experiência que implica o corpo, podem nos ajudar a refletir sobre nossa condição de sujeitos padecentes. Afinal, como afirma Joel Birman (1997): "ante o desamparo do sujeito na cultura, não existe cura possível, mas somente a perspectiva de construir um estilo subjetivo que seja capaz de lidar com os conflitos insuperáveis" (BIRMAN, 1997, p. 11-12. Grifos nossos). Tanto o pensamento de Schopenhauer como o de Freud apontam nessa direção, ainda que de maneiras distintas.

\section{REFERÊNCIAS BIBLIOGRÁFICAS}

ANZIEU, Didier. (1989) O Eu-pele. São Paulo: Casa do Psicólogo.

ASSOUN, P-L. (1978) Freud: a filosofia e os filósofos. Trad. Hilton Japiassu. Rio de Janeiro: Francisco Alves. . (1996) O Corpo: o Outro metapsicológico. In: Id. Metapsicologia freudiana: uma introdução. Rio de Janeiro: Jorge Zahar.

BALMÈS, F. (2004) La experiencia analítica como experiencia del ser. In: ZUBERMAN, J. et alli. El psicoanálisis como experiencia. Buenos Aires: Letra Viva.

BARBOSA, M. (2003) Schopenhauer e o corpo. La Salle, vol. 8, n. 1, p. 31-54.

BARBOZA, J. (2005) Infinitude subjetiva e estética - natureza e arte em Schelling e Schopenhauer. São Paulo: UNESP.

BIRMAN, J. (1997) Sobre o mal-estar na modernidade. In: Id. Estilo e modernidade em psicanálise. São Paulo: Editora 34.

. (2012) O sujeito na contemporaneidade: espaço, dor e desalento na atualida-

de. Rio de janeiro: Civilização Brasileira. 
CACCIOLA, M. L. (1991) Schopenhauer e o inconsciente. In: KNOBLOCH, Felícia. O inconsciente: várias leituras. São Paulo: Escuta.

. (1994) Schopenhauer e a questão do dogmatismo. São Paulo: EDUSP.

CARVALHO, A. C. (2006) A teoria invisível. In: CARVALHO, A. C. e FRANÇA, C. P. (Org.). Estilos do xadrez psicanalítico: a técnica em questão. Rio de Janeiro: Imago.

COSTA, J. F. (2004) O vestígio e a aura: corpo e consumismo na moral do espetáculo. Rio de Janeiro: Garamond.

DEJOURS, C. (1991) Repressão e subversão em psicossomática: pesquisas psicanalíticas sobre o corpo. Rio de Janeiro: Jorge Zahar.

DEBONA, V. (2010) Schopenhauer e as formas da razão: o teórico, o prático e o ético-místico. São Paulo: Annablume.

DRAWIN, C. R. (2006) Estrutura e história: uma dialética no caminho da psicanálise. In: CARVALHO, A. C. e FRANÇA, C. P. (Org.). Estilos do xadrez psicanalítico: a técnica em questão. Rio de Janeiro: Imago.

FERNANDES, M. H. (2003) Corpo. São Paulo: Casa do Psicólogo.

FONSECA, E. R. (2009) Psiquismo e vida - o conceito de impulso nas obras e Freud, Schopenhauer e Nietzsche. São Paulo: Departamento de Filosofia. 329 p. Tese de doutorado em Filosofia. USP.

nhauer e Freud. Curitiba: Editora UFPR.

. (2016) Uma estreita passagem: O conceito de corpo nas obras de Schope-

FREUD, S. (1895/1996) Proyecto de psicologia. Trad. José Luis Etcheverry. Buenos Aires: Amorrortu Editores, volumen 1, p. 325-446.

. (1900/1996) La interpretación de los sueños. Trad. José Luis Etcheverry. Buenos Aires: Amorrortu Editores, volumen 5, p. 504-611.

. (1905 [1901]/1996) Fragmento de análisis de un caso de histeria. Trad. José Luis Etcheverry. Buenos Aires: Amorrortu Editores, volumen 7, p. 3-100.

. (1908/1996) La moral sexual "cultural" y la nerviosidad moderna. Trad. José Luis Etcheverry. Buenos Aires: Amorrortu Editores, volumen 9, p. 161-181.

. (1914/1996) Contribuición a la historia del movimiento psicoanalítico. Trad. José Luis Etcheverry. Buenos Aires: Amorrortu Editores, volumen 14, p. 3-64.

. (1917 [1915]/1996) Duelo y melancolia. Trad. José Luis Etcheverry. Buenos Aires: Amorrortu Editores, volumen 14, p. 237-255.

. (1920/1996) Más allá del principio de placer. Trad. José Luis Etcheverry. Buenos Aires: Amorrortu Editores, volumen 18, p. 3-62. 
. (1923/1996) El yo y el ello. Trad. José Luis Etcheverry. Buenos Aires: Amorrortu Editores, volumen 19, p. 3-66.

. (1924/1996) El problema económico del masoquismo. Trad. José Luis Etcheverry. Buenos Aires: Amorrortu Editores, volumen 19, p. 175-189.

. (1930 [1929]/1996) El malestar en la cultura. Trad. José Luis Etcheverry. Buenos Aires: Amorrortu Editores, volumen 21, p. 59-140.

. (1937a/1996) Análisis terminable y interminable. Trad. José Luis Etcheverry. Buenos Aires: Amorrortu Editores, volumen 23, p. 219-254.

. (1937b/1996) Construcciones en el análisis. Trad. José Luis Etcheverry. Buenos Aires: Amorrortu Editores, volumen 23, p. 257-27.

GARDNER, S. (2007) Schopenhauer, Will and the Unconscious. In: JANAWAY, C. The Cambridge Companion to Schopenhauer. Cambridge: University Press.

HAMLYN, D. (2007) Schopenhauer and Knowledge. In: JANAWAY, C. (Coord.). The Cambridge Companion to Schopenhauer. Cambridge: University Press.

JANAWAY, C. (Coord.). (2007) The Cambridge Companion to Schopenhauer. Cambridge: University Press.

KRISTEVA, J. (2001) As novas doenças da alma. Rio de Janeiro: Rocco.

LE BRETON, D. (2013) Antropologia do corpo e modernidade. Trad. Fábio dos Santos Creder Lopes. 3. ed. Petrópolis: Vozes.

LOUREIRO, I. (2014) Psicanálise e filosofia: em busca de uma noção de experiência. São Paulo, (artigo no prelo).

MARTINS, E. C. (2006) Freud e Schopenhauer: os limites de um diálogo sobre a moral. São Carlos: Centro de Educação em Ciências Humanas. 157 p. Dissertação de Mestrado em Filosofia. UFSCar.

MAURANO, D. (1995) Nau do desejo: o percurso da ética de Freud a Lacan. Rio de Janeiro: Relume-Dumará; Alfenas: Unifenas.

MENDONÇA, M. M. (2006) As incidências da repetição no corpo, pela via da dor. Belo Horizonte: Faculdade de Filosofia e Ciências Humanas. 124 p. Dissertação de Mestrado em Psicologia. UFMG.

. (2015) A dimensão ética do corpo nos pensamentos de Schopenhauer e de Freud. Belo Horizonte: Faculdade de Filosofia e Ciências Humanas. 331 p. Tese de Doutorado em Filosofia. UFMG.

MOREIRA, J. (1998) Freud e a filosofia: a herança schopenhaueriana. In: Psicanálise e Universidade, São Paulo, (8), $1^{\circ} \stackrel{\circ}{\text { sem. }}$ 
PALAO, A. (1990) La sabiduria budista del vacío. In: URDANIBIA, J. (Coord.) Los Antihegelianos: Kierkgaard y Schopenhauer. Barcelona: Anthropos, p. 211-37.

REIS, M. L. O. (2015) Da experiência de perda à perda de experiência: um estudo sobre a Erfahrung na teoria psicanalítica, na filosofia e na clínica. São Paulo: Instituto de Psicologia. 132 p. Tese de Doutorado em Psicologia. USP.

ROCHA, Z. (2008) A experiência psicanalítica: seus desafios e vicissitudes, hoje e amanhã. Ágora, Rio de Janeiro, vol. XI, n. 1, p. 101-116, jan./jun.

. (2010) Freud e a filosofia alemã na segunda metade do século XIX. In: Id. Freud entre Apolo e Dionísio - recortes filosóficos, ressonâncias psicanalíticas. São Paulo: Edições Loyola.

SAFATLE, V. (Org.). 2008. A filosofia após Freud. São Paulo: Humanitas.

SCHOPENHAUER, A. 1813) Sobre la cuadruple raiz del principio de razon suficiente. Trad. Vicente Romano Garcia. Buenos Aires: Aguilar.

. (1819/2005) O mundo como vontade e como representação. Tomo I. Trad., apresentação, notas e índices Jair Barboza. São Paulo: UNESP.

. (1819/2005) Crítica da filosofia kantiana. In: Id. O mundo como vontade e como representação. Tomo I. Trad., apresentação, notas e índices Jair Barboza. São Paulo: UNESP, p. 521663.

. (1819/2005) O mundo como vontade e como representação. Tomo II. Trad., apresentação, notas e índices Jair Barboza. São Paulo: UNESP.

. (1819/2005) O mundo como vontade e como representação. Tomo II. Trad., apresentação, notas e índices Jair Barboza. São Paulo: UNESP, Suplementos ao livro primeiro, capítulos $1,2,6$ e 7 .

. (1841/2001) Sobre o fundamento da moral. Trad. Maria Lucia Cacciola. São

Paulo: Martins Fontes.

. (1851/1974) Parerga e Paralipomena, capítulo VIII, \$115-117. In: Coleção Os Pensadores. São Paulo: Abril Cultural.

. (1851/2006) Aforismos para a sabedoria de vida. Trad. Jair Barboza. São Pau-

lo: Martins Fontes.

. (1851/2012) Sobre a ética. Organização e tradução Flamarion Caldeira Ra-

mos. São Paulo: Hedra.

SOARES, D. Q. F. (2011) O gênio e o santo na filosofia de Schopenhauer. Revista Voluntas: Estudos sobre Schopenhauer, vol. 2, n. 1, pp. 83-94. 


\section{NOTAS}

1. Doutora em Filosofia pela UFMG; professora adjunta do Curso de Psicologia da FEAD/MG; marinella.mendonca@fead.br / marinellamorgana@hotmail.com.

2. A literatura comparativa entre as ideias de Freud e Schopenhauer é extensa e diversificada e, dentre as pesquisas mais relevantes, podemos destacar: ASSOUN, Paul-Laurent. 1978. Freud: a filosofia e os filósofos. Rio de Janeiro: Francisco Alves; FREUD, Sigmund. 1914/1996. “Contribuición a la historia del movimiento psicoanalítico”, Amorrortu Editores, volumen 14; GARDNER, Sebastian. 2007. Schopenhauer, Will and the Unconscious. In: JANAWAY, Christopher. The Cambridge Companion to Schopenhauer. Cambridge: University Press; JULIUSBURGER, Otto [1867-1952]. Schopenhauer e a psicologia do presente, apud CACCIOLA. Schopenhauer e o inconsciente. In: KNOBLOCH, Felícia. 1991. O inconsciente: várias leituras. São Paulo: Escuta; MOREIRA, Jacqueline. 1998. Freud e a filosofia: a herança schopenhaueriana. In: Psicanálise e universidade, São Paulo, (8), 1o sem.; ROCHA, Zeferino. 2010. Freud e a filosofia alemã na segunda metade do século XIX. In: id. Freud entre Apolo e Dionísio: recortes filosóficos, ressonâncias psicanalíticas. São Paulo: Edições Loyola; SAFATLE, Vladimir. (Org.) 2008. A filosofia após Freud. São Paulo: Humanitas. Com relação aos temas do corpo e da ética, não podemos deixar de citar: MARTINS, Eduardo de Carvalho. 2006. Freud e Schopenhauer: os limites de um diálogo sobre a moral. Dissertação de Mestrado. UFSCar; FONSECA, Eduardo Ribeiro. 2009. Psiquismo e vida - o conceito de impulso nas obras e Freud, Schopenhauer e Nietzsche. Tese de doutorado. USP. Nesta pesquisa, Fonseca afirma que, apesar das destinações próprias de cada obra, há uma profícua aproximação entre Freud, Schopenhauer e Nietzsche. Concordamos com o autor no que se refere aos nossos autores, Freud e Schopenhauer e, ao seu lado, sustentamos que nossa intenção não é transformar a psicanálise, um método teórico e clínico de tratamento do sofrimento humano, em uma filosofia. Nesse sentido, como lembra Fonseca, precisamos preservar a autonomia dos campos de saber que se comunicam (2009, p. 232). Cf., ainda, id. 2016. Uma estreita passagem: O conceito de corpo nas obras de Schopenhauer e Freud. Curitiba: Editora UFPR.

3. A bibliografia que trata do tema do corpo no pensamento freudiano é extensa. Como um breve exemplo de tal extensão, podemos citar: ANZIEU, Didier. 1989. O Eu-pele. São Paulo: Casa do Psicólogo; ASSOUN, Paul-Laurent. 1996. O Corpo: o Outro metapsicológico. In: id. Metapsicologia freudiana: uma introdução. Rio de Janeiro: Jorge Zahar; COSTA, Jurandir Freire. 2004. O vestígio e a aura: corpo e consumismo na moral do espetáculo. Rio de Janeiro: Garamond; DEJOURS, Christophe. 1991. Repressão e subversão em psicossomática: pesquisas psicanalíticas sobre o corpo. Rio de Janeiro: Jorge Zahar; FERNANDES, Maria Helena. 2003. Corpo. São Paulo: Casa do Psicólogo; MENDONÇA, Marinella Morgana. 2006. As incidências da repetição no corpo, pela via da dor. Dissertação de Mestrado: UFMG; id. 2015. A dimensão ética do corpo nos pensamentos de Schopenhauer e de Freud. Tese de Doutorado: UFMG, capítulo 1; KRISTEVA, Júlia. 2001. As novas doenças da alma. Rio de Janeiro: Rocco.

4. Sobre a teoria epistemológica de nosso autor, cf. CACCIOLA, Maria Lúcia. 1994. Schopenhauer e a questão do dogmatismo. São Paulo: EDUSP; DEBONA, Vilmar. 2010. Schopenhauer e as formas da razão: o teórico, o prático e o ético-místico. São Paulo: Annablume; HAMLYN, David. 2007. Schopenhauer and Knowledge. In: JANAWAY, Christopher. (Coord.). The Cambridge Companion to Schopenhauer. Cambridge: University Press; MENDONÇA, Marinella Morgana. 2015. A dimensão ética do corpo nos pensamentos de Schopenhauer e de Freud. Tese de Doutorado: UFMG, capítulo 4; SCHOPENHAUER, Arthur. 1813. Sobre la cuadruple raiz del principio de razon suficiente. Trad. Vicente Romano Garcia. Buenos Aires: Aguilar; id. 1819/2005. Crítica da filosofia kantiana. In: id. O mundo como vontade e como representação. Tomo I. Trad., apresentação, notas e índices Jair Barboza. São Paulo: UNESP, p. 521663; id. O mundo como vontade e como representação. Tomo II. Trad., apresentação, notas e índices Jair Barboza. São Paulo: UNESP, Suplementos ao livro primeiro, capítulos 1, 2, 6 e 7.

5. BARBOZA, 2005. Nota de rodapé n. 2. In: SCHOPENHAUER. O mundo como vontade e como representação, Tomo I, livro II, $\$ 18$, p. 157. Grifos do tradutor.

6. Cf. FREUD, Sigmund. “Duelo y melancolia”. 1917/1996. Amorrortu Editores, volumen 14. 
7. Cf. FREUD, Sigmund. 1923/1996. El yo y el ello. Amorrortu Editores, volumen 19; MENDONÇA. 2006. As incidências da repetição no corpo, pela via da dor. Dissertação de Mestrado: UFMG.

8. Não podemos deixar de ressaltar que a pulsão, em Freud, não se esgota e, tampouco, se mortifica, como pode ocorrer com a vontade schopenhaueriana. Logo, é preciso termos em mente que o sujeito, para Freud, é um ser de conflito do início ao fim de seus dias, e, justamente por isso, não temos garantias de que um tratamento psicanalítico, direcionado por um psicanalista que "domine" a técnica, vá produzir uma experiência de esvaziamento de gozo do corpo de um paciente, que o procura buscando sofrer menos. Pode acontecer que a pulsão encontre outras vias para se manifestar, tornando o ouvinte, no caso o psicanalista, um álibi do sintoma do sujeito. Se isso acontece, estamos diante dos poderes "demoníacos" da pulsão de morte. Cf. FREUD, Sigmund. 1920/1996. Más allá del principio del placer. Amorrortu Editores, volumen 18; id. "El problema económico del masoquismo”. 1924/1996. Amorrortu Editores, volumen 19; id. 1930/1996. El malestar en la cultura. Amorrortu Editores, volumen 21.

9. Os aspectos referentes ao modo como o conceito de experiência é visto pela psicanálise podem ser mais bem investigados em REIS, Maria Letícia. 2015. Da experiência de perda à perda da experiência: um estudo sobre a Erfahrung na teoria psicanalítica, na filosofia e na clínica. Tese de doutorado: USP. Agradecemos à autora pela interlocução fecunda sobre esse tema, contribuindo para aproximarmos Schopenhauer de Freud, no tocante às relações que a "experiência ética do corpo", presente no pensamento de ambos, acarreta para o nosso estudo.

10. Cf. SOARES, Daniel Quaresma Figueira. 2011. O gênio e o santo na filosofia de Schopenhauer. Revista Voluntas: Estudos sobre Schopenhauer, vol. 2, n.1, p.83-94. Seguindo a trilha de Schopenhauer, o autor trabalha as semelhanças e diferenças entre essas duas figuras da negação da vontade, ressaltando o fato de que o santo pode alcançar, via ascese, um estado mais duradouro de tal negação.

11. Cf. SCHOPENHAUER, Arthur. 1819/2005. O mundo como vontade e como representação. Tomo I. Tradução, apresentação, notas e índices Jair Barboza. São Paulo: UNESP, Livro IV, \$ 68, p. 480-503; id. 1859/2015. O mundo como vontade e como representação. Tomo II. Tradução, apresentação, notas e índices Jair Barboza. São Paulo: UNESP, Suplementos ao Livro IV, capítulos 48 e 49, p. 719-61; id. 1851/2012. Sobre a ética. Organização e tradução Flamarion Caldeira Ramos. São Paulo: Hedra, p. 35-84.

12. Cf. BARBOSA, Melissa. 2003. Schopenhauer e o corpo. La Salle, vol. 8, no. 1, p. 31-54. Ao comentar aspectos referentes à participação do corpo no processo de negação da vontade, a autora corrobora o ponto de vista que vimos apresentando, ou seja, o corpo está intimamente envolvido não somente nos aspectos relativos à afirmação da vontade de vida, mas, sobretudo, em sua negação. Barbosa salienta que apenas o homem é capaz de negar-se, apenas o homem como fenômeno da vontade, ou, melhor dizendo, o homem encarnado. Para essa autora, o corpo deve estar sempre pressuposto, pois, "arrancar a vida do corpo não leva ninguém à salvação. Somente quem vive e, durante a vida, mortifica a vontade, pode livrar-se do mundo do sofrimento” (2003, p. 54. Grifos nossos).

13. Cf. PALAO, Antonio. 1990. La sabiduria budista del vacío. In: URDANIBIA, Javier. (Coord.) Los Antihegelianos: Kierkgaard y Schopenhauer. Barcelona: Anthropos, p. 211-37. Segundo o autor, a ética schopenhaueriana é paradoxal: uma vez que o mundo é a autocontradição da vontade, sua negação pode ser entendida como sendo um retorno à sua identidade mesma, um repouso lógico, isto é, tal negação não passa da negação de uma contradição. Schopenhauer é incisivo ao afirmar que o que podemos entrever por trás da compaixão e da caridade é o cuidado com o outro que, em essência, é idêntico a nós mesmos, que nos reconhecemos em nossa condição comum de sujeitos encarnados. "A caridade e a compaixão são semelhantes aos cuidados com o próprio corpo, à atenção com as próprias feridas" (1990, p. 221). Nesse sentido, sustentamos, ao lado de Palao, que o dito védico Tat Tawm Asi (tu és isto) deve ser entendido a partir da lógica da identidade. Isto significa dizer: você é este corpo, absolutamente idêntico ao meu corpo próprio. Cf. também SCHOPENHAUER, Arthur. 1851/1974. Parerga e Paralipomena, capítulo VIII, \$115-117. In: id. Coleção Os Pensadores. São Paulo: Abril Cultural. Nessa passagem, nosso autor se refere à fórmula tat twam asi como sendo a verdadeira essência de sua ética. 
14. A introdução do conceito de pulsão de morte não somente teve efeitos profundos no conjunto da teorização freudiana, mas produziu certa inflexão pessimista em sua teoria da cultura. Apesar de sempre se manter como um Aufklärer, o psicanalista vienense manifesta certo desencanto com o curso da civilização e, portanto, com a efetividade de normas racionais para alavancar o progresso. Não obstante, não mergulha no niilismo, pois permanece fiel à ética de inclinação estoica que impulsiona o cuidado de si e do outro. O cuidado, que aqui aproximamos à compaixão, como uma ética edificante do amor ao próximo. A crítica freudiana do "amor ao próximo", exposta no capítulo cinco de $O$ mal-estar na civilização (1930), consiste, justamente, na consciência da motivação egoísta que também anima o nosso "próximo". No entanto, as dores do mundo e, especialmente, as dores do nosso corpo pulsional, o sofrimento do sujeito encarnado, também mostram o quanto o outro partilha, como nós, da estranheza dessa vontade de vida cega e incoercível. Cf. MENDONÇA, Marinella Morgana. 2015. A dimensão ética do corpo nos pensamentos de Schopenhauer e de Freud. Tese de Doutorado: UFMG, capítulo 7: O sujeito padecente: por uma ética psicanalítica da compaixão.

15. Cf. LE BRETON, David. 2013. Antropologia do corpo e modernidade. Tradução de Fábio dos Santos Creder Lopes. 3. ed. Petrópolis: Vozes. Para alcançarmos uma abordagem mais detalhada acerca das questões antropológicas que envolvem a condição "pathológica" do homem contemporâneo, devemos examinar os aspectos relativos ao corpo. Nessa obra, o sociólogo conduz tal empreitada, tomando o corpo como seu fio condutor. Dentre várias ideias, o autor defende que o corpo é propício a uma análise antropológica justamente por ser a existência humana uma experiência eminentemente corporal. Desse modo, empreende uma espécie de genealogia do corpo moderno. Entendemos que nossa pesquisa está na mesma direção das análises de Le Breton, mesmo que modestamente, uma vez que tentamos ressaltar, por meio dos pensamentos de Schopenhauer e de Freud, a importância do lugar do corpo, aos olhos do homem, como sendo algo misterioso ou enigmático, e que carece, pois, de uma resposta.

16. É importante deixar claro que utilizamos aqui a expressão "ética da psicanálise” em sua acepção de experiência clínica, nos moldes indicados por Freud, ou seja, uma experiência em que analista e cliente conversam. Cf. CARVALHO, Ana Cecília. 2006. A teoria invisível. In: CARVALHO, Ana Cecília e FRANÇA, Cassandra Pereira. (Org.). Estilos do xadrez psicanalítico: a técnica em questão. Rio de Janeiro: Imago.

17. Nem todo processo psicanalítico produz uma escuta ética que, por sua vez, permite um esvaziamento de gozo do corpo. Em que consiste tal escuta ética, então? Não pode ser um simples acolhimento de uma pessoa em estado de sofrimento, uma vez que o Eu que fala não esgota o sujeito que padece. Esta seria uma contribuição da psicanálise para o aprofundamento de uma ética da compaixão e é, certamente, um tema a ser mais bem desenvolvido em uma continuação de nossa pesquisa. Cf. BALMÈS, François. 2004. La experiencia analítica como experiencia del ser. In: ZUBERMAN, José et alli. El psicoanálisis como experiencia. Buenos Aires: Letra Viva.

18. Expressão utilizada por Zeferino Rocha ao caracterizar Freud. Cf. ROCHA. 2008. A experiência psicanalítica: seus desafios e vicissitudes, hoje e amanhã. Ágora, Rio de Janeiro, vol. XI, n.1, p. 101-116, jan./jun. 